\title{
CFD Modelling of Flow and Temperature Profiles in a Semi-Continuous Coal Stove
}

\author{
C. Prinsloo, F. Van der Merwe, F. Conradie and F. Bopape
}

\begin{abstract}
Approximately 1.5 Million low-income South-African households rely on alternative energy resources like the burning of coal in metal drums. To address the health risks associated with the resulting indoor air pollution, the North-West University developed an improved coal-stove prototype. The unusual temperature profiles obtained during the stove's performance evaluations, were investigated using Siemens's $N X-12^{\mathrm{TM}}$ together with STAR-CCM+ TM modelling software, by simulating the velocity and temperature profiles inside the stove. Instead of employing a combustion model, which will be computationally intensive, a constant heat source was used to approximate the combustion process. From the simulation output it was observed that the obstructed flow through the hopper was causing the high temperature in the chamber. Some temperature observations could be accurately predicted by the model under the assumed conditions, however, the inclusion of a combustion and detailed packed bed heat transfer model will improve the temperature prediction capability of the simulation
\end{abstract}

Keywords-Coal Stove, Indoor Air Pollution, STAR-CCM+, NX-12, Porous region

\section{INTRODUCTION}

Despite the government's strides in providing electricity to many low-income households over the past 20 years, approximately 1.5 million households are still relying on other means of energy [1]. Up to $80 \%$ of these households have access to electricity but choose to use coal due to its availability, affordability and cultural significance [2], [3]. Poorly designed coal-stoves lead to the incomplete combustion of coal and consequently, dangerous quantities of carbon monoxide, sulphur dioxide and nitrogen dioxide are being emitted within households [4]. Furthermore, the long-term exposure to indoor particulate matter due to the burning of organic materials caused approximately 4 million fatalities worldwide in 2016 [5]. The two most common strategies used to address the problem at hand include the use of alternative fuel sources and improving the design of the coal-stoves.

Manuscript received October 25, 2019. This work was supported in part by the North-West University - Potchefstroom.

C. Prinsloo is with the North-West University, Potchefstroom, SA.

F. Van der Merwe is with the department of chemical engineering, North-West University, Potchefstroom, SA.
Examples of the first strategy includes the use of low-smoke fuels or more efficient ignition procedures [6], [7]. However, changing the fuel used by low-income households requires that additional factors such as re-education, accessibility and price be addressed, despite the promising results associated with its use [8]. For this reason, the second strategy seems equally feasible. During combustion, moisture, volatiles and flue gasses are released while only non-combustible materials remain in the stove [9]. Ash build-up decreases the coal's number of active sites available to react with oxygen and lowers the char combustion rate [10]. To circumvent this occurrence, improved designs incorporate at the very least a grate or fuel support through which the ash can be removed by agitation [11]-[13]. Other common improvements found include chimneys [7], [14], heat resistant construction materials [11] and air flow controllers. The air opening of a domestic coal-stove is normally opened completely during cooking to allow for maximum temperatures to be achieved within the stove, demonstrating the relationship between the air flowrate and temperature [15].

Consequently, an improved stove was developed by the North-West University's Faculty of Engineering in Potchefstroom, and experiments were performed to test the performance [16],[17]. To allow for semi-continuous operation during colder seasons, a coal hopper chamber was included since the continuous addition of coal will allow for prolonged periods of space heating. However, an inefficient energy distribution was identified following the performance evaluations on the stove. The main concern was the temperature in the hopper chamber reaching temperatures equal to that in the combustion chamber. Similar inefficiencies in process equipment are often investigated using a computational fluid dynamics (CFD) analysis given the many advantages associated with its use [18]. The use of CFD in stove research dates to the 1990's [19]. Since then, work has been done to decrease carbon monoxide emissions by $80 \%$ by using CFD to determine the optimal quantity of air, shape of deflector plates, combustion chamber shape and air direction [20]. In another study, the recirculation and optimal process conditions for mixing requirements was determined using CFD [21]. Many additional articles can be found where CFD analysis was used to determine the most suitable flow configurations and velocity profiles in equipment which maximizes the efficiency thereof [22]-[24]. In this project, CFD allowed the analysis of variables 
throughout the stove wherein experimental procedures would have failed to provide the required insight.

\section{Model DeVelopment}

\section{A. Siemens $N X-12^{\mathrm{TM}}$}

Using Siemens $N X-12^{\mathrm{TM}}$, an inverted stove assembly was constructed. This means that all the solid components that collectively form part of the stove, was inserted as cut-outs from a "solid" gas region. This is illustrated by Fig. 1. In order to simulate the combustion of coal without the use of a combustion model, two blocks were inserted into the combustion region of the oven in order to emulate a coal bed as illustrated by the light-coloured region in Fig. 2. Additionally, two different changes were made to the stove design and the modified versions were simulated in the exact fashion as the original. The first modification entailed closing the top of the stove gas exit channel next to the chimney opening inside the stove to manipulate the flow and energy distribution within the heat exchanger chamber. The second modification entailed altering the bridge between the coal feed hopper and the combustion chamber in order to observe whether the temperature and flow profiles within the hopper and combustion chambers would dramatically change. The first and second alterations can be seen in Fig. 3 and Fig. 4 respectively.

\section{B. STAR-CCM+TM}

\section{Start-Up and Meshing}

The coal assemblies were exported as parasolid files from $\mathrm{NX}-12^{\mathrm{TM}}$ and imported to STAR-CCM+TM as a surface mesh. Upon importing the parasolid, the software automatically created three leaf-level computer-aided design (CAD) parts which was renamed coal bottom, coal top and gas respectively. The three leaf-level parts were then assigned to regions with every part receiving a region and each part surface receiving a boundary.

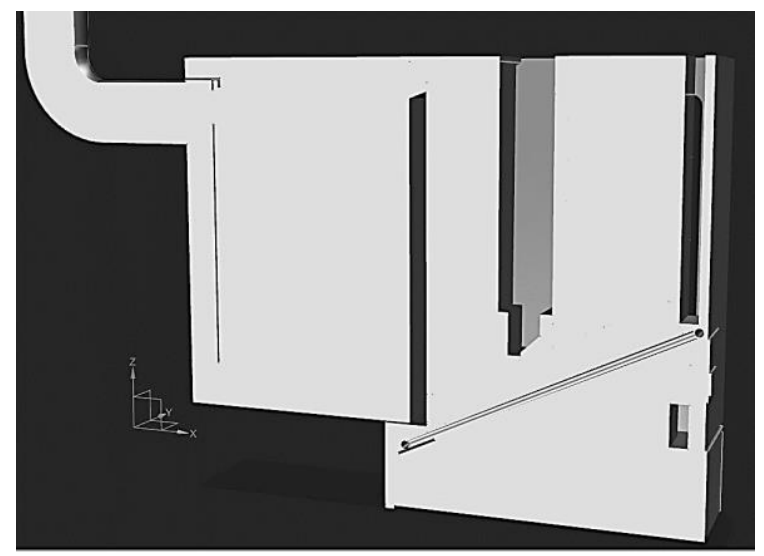

Fig. 1. A section of the stove to illustrate the inverted assembly created in Siemens NX-12.

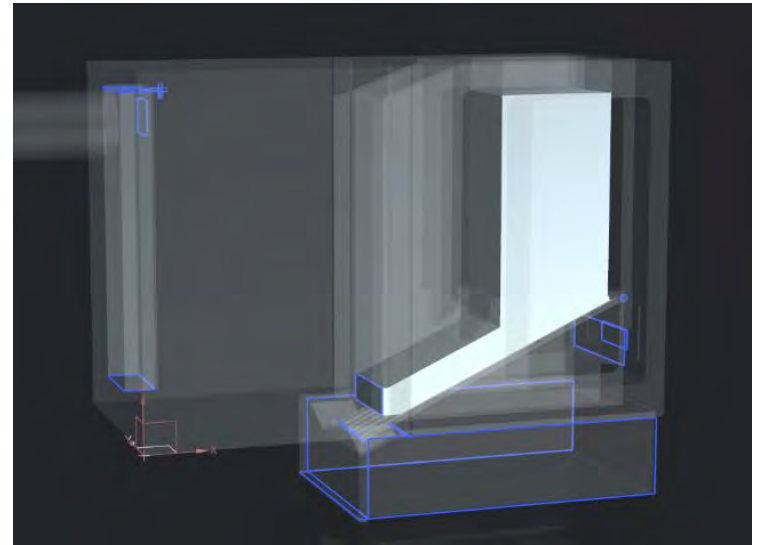

Fig. 2. Two blocks used to recreate a coal bed.

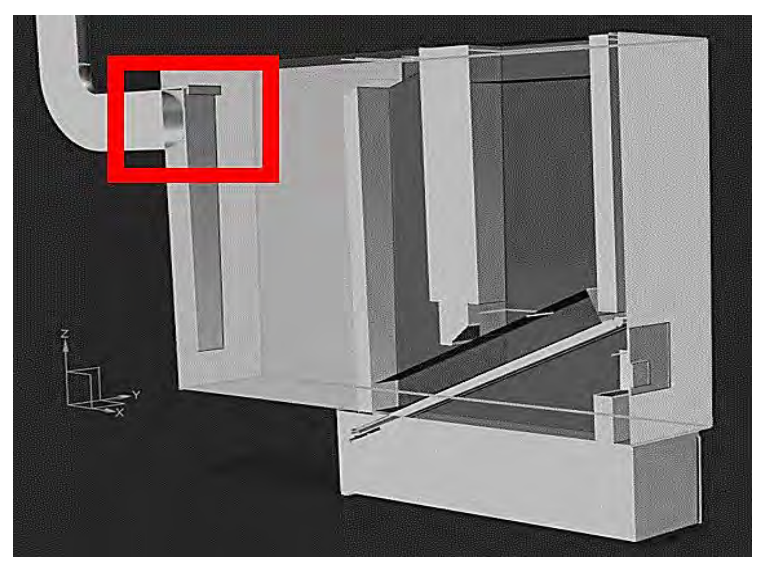

Fig. 3: Indication of the first stove modification.

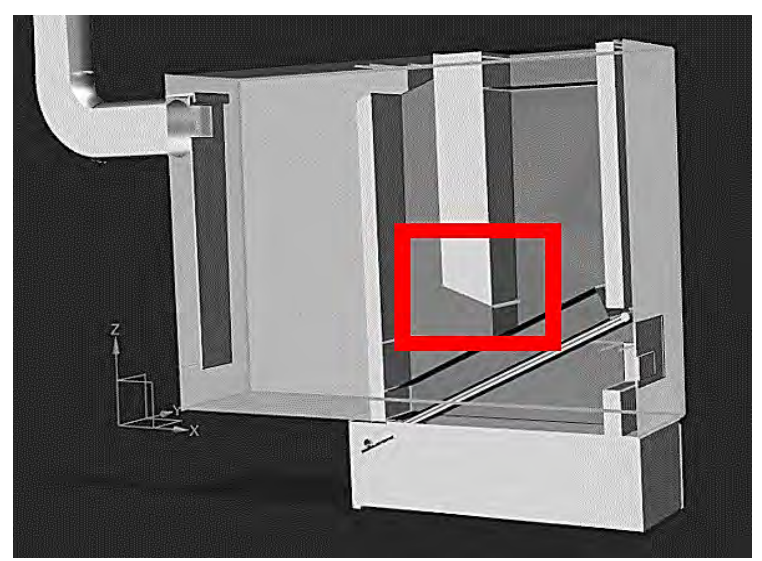

Fig. 4: Indication of the second stove modification.

The top and bottom coal blocks were changed to porous regions and each of the 3 newly created regions were given an internal and in-place interface, suitable for both heat and mass transfer across the region boundaries. Per-region meshing was enabled after which a polyhedral- and prism layer mesher was chosen together with a surface remesher. The prism layer mesher automatically created a finer grid around regions with sharp edges or small openings where the flow descriptions became complicated. 
The mesh base size was chosen by completing a grid independent study during which the temperature at the top and bottom of the hopper chamber was monitored. The temperature at the two monitor points was noted after decreasing the base size and a new state of convergence was reached. The temperature at the previous base size was subtracted from the temperature at the new base size and the difference was plotted and is shown in Fig. 5. Even though a change in temperature between a base size of $10 \mathrm{~mm}$ and $8 \mathrm{~mm}$ could still be observed, the time to reach convergence doubled. For this reason, the final mesh base size was chosen to be $10 \mathrm{~mm}$ as presented in Fig. 6.

\section{Fluid Mechanics}

It is common practice in the world of CFD modelling to use the compressed form of the Reynolds-averaged Navier-Stokes (RANS) equations as given by (1) to describe flow within a domain [25].

$$
\frac{\partial\left(\bar{v}_{\mathbf{i}}\right)}{\partial t}+\frac{\partial\left(\bar{v}_{\mathbf{i}} \overline{\mathbf{v}}_{\mathbf{j}}\right)}{\partial \mathbf{x}_{\mathbf{j}}}=-\frac{1}{\rho} \frac{\partial(\overline{\mathbf{p}})}{\partial \mathbf{x}_{\mathbf{i}}}+\mathbf{v} \frac{\partial^{2}\left(\overline{\mathbf{v}}_{\mathbf{i}}\right)}{\partial \mathbf{x}_{\mathbf{j}} \mathbf{x}_{\mathbf{j}}}-\frac{\partial\left(\overline{v^{\prime} v^{\prime}}\right)}{\partial \mathbf{x}_{\mathbf{j}}}
$$

Here, $\boldsymbol{v}^{\prime}$ represents the fluctuating velocity component, $\mathrm{p}$ represents pressure, $\rho$ is the density of the gas and $\bar{\phi}$, with $\phi$ any vector, represents the time averaged value of that variable. The term on the farthest right of (1) is termed the Reynolds stress term. This term represents the contribution of turbulence to the shear stress [26] and is most commonly calculated with the Boussinesq equation as given by (2) [27].

$$
\tau_{i j}=-\overline{v^{\prime} v^{\prime}}=-\frac{2 k}{3}+\mu_{t}\left(\frac{\partial\left(v_{i}\right)}{\partial x_{j}}+\frac{\partial\left(v_{j}\right)}{\partial x_{i}}\right)
$$

$\tau_{i j}$ Represents the Reynolds stress term, $\mu_{t}$ is known as the turbulent eddy viscosity and $\mathrm{k}$ represents turbulent kinetic energy.

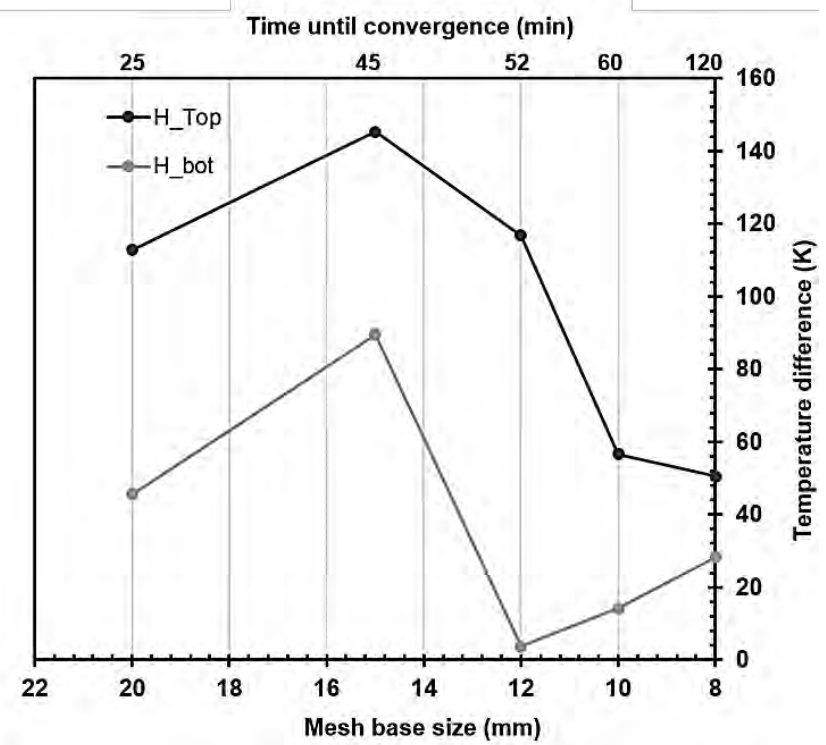

Fig. 5: Grid independence study using temperatures from the top and the bottom of the hopper chamber.

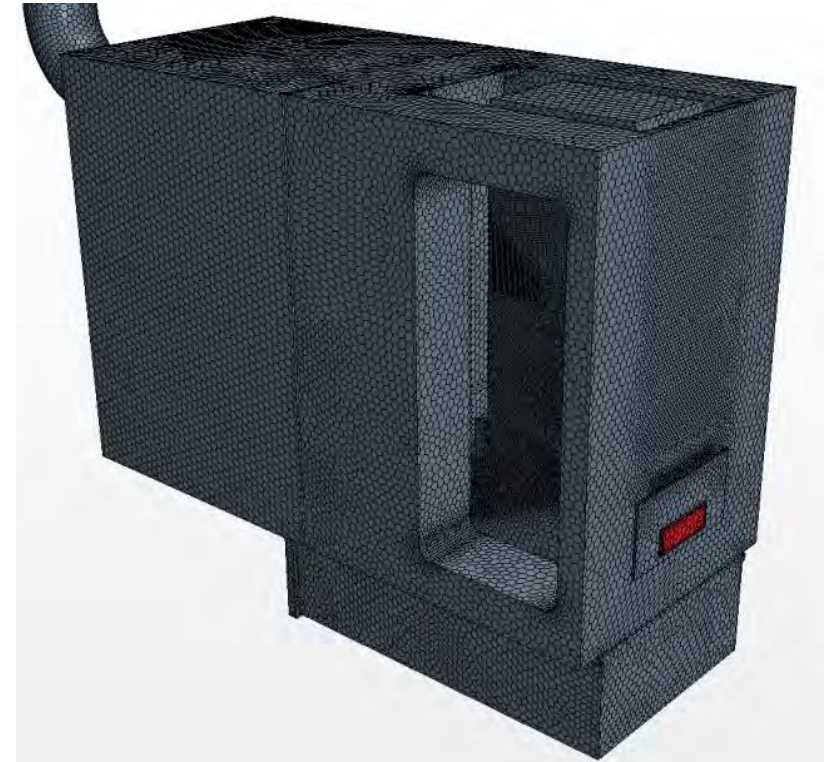

Fig. 6: $10 \mathrm{~mm}$ Mesh used to create the control volume grid.

The turbulent eddy viscosity is calculated by using a turbulence model chosen from one of seven commonly found classes [28]. STAR_CCM+TM uses a turbulence model from the two-equation model class known as the $\mathrm{k}-\varepsilon$ model proposed by Jones and Launder, although the k- $\omega$ model is also a popular closure model used for CFD applications [29]. The standard k- $\varepsilon$ (SKE) model as used by the software is given by (3) - (5).

$$
\begin{gathered}
\frac{\partial\left(k \boldsymbol{v}_{j}\right)}{\partial x_{j}}=\frac{1}{\rho} \frac{\partial}{\partial x_{j}}\left[\left(\mu+\frac{\mu_{t}}{\sigma_{k}}\right) \frac{\partial k}{\partial x_{j}}\right]+\frac{P_{k}}{\rho}-\epsilon \\
\frac{\partial\left(\epsilon \boldsymbol{v}_{j}\right)}{\partial x_{j}}=\frac{1}{\rho} \frac{\partial}{\partial x_{j}}\left[\left(\mu+\frac{\mu_{t}}{\sigma_{\epsilon}}\right) \frac{\partial \epsilon}{\partial x_{j}}\right]+C_{1} \frac{\epsilon}{k} \frac{P_{k}}{\rho}-C_{2} \frac{\epsilon^{2}}{k} \\
\mu_{t}=\rho C_{\mu} \frac{k^{2}}{\epsilon}
\end{gathered}
$$

Here, $\epsilon$ represents the dissipation rate, $\sigma_{k}, \sigma_{\epsilon}, C_{\mu}, C_{1}$ and $C_{2}$ represent model constants and $P_{k}$ is a source term for turbulent kinetic energy. Equations (3)-(5) has a poor performance record in complex flow domains [30] which is improved by using the realizable $k-\varepsilon$ (RKE) model. The RKE model differs from the SKE model in two ways. The first is the use of a transport equation to calculate the dissipation rate (6) and the second is the use of a function to determine $C_{\mu}$ as given in (7).

$$
\begin{gathered}
\frac{\partial\left(\epsilon v_{j}\right)}{\partial x_{j}}=\frac{\partial}{\partial x_{j}}\left[\left(\frac{v_{t}}{\sigma_{\epsilon}}\right) \frac{\partial \epsilon}{\partial x_{j}}\right]+C_{1} S \epsilon-C_{2} \frac{\epsilon^{2}}{k+\sqrt{v \epsilon}} \\
C_{\mu}=\left(A_{0}+A_{s} v^{*} \frac{k}{\epsilon}\right)^{-1}
\end{gathered}
$$

Where $A_{0}=4.04$, and $A_{s}, \vartheta, W$ and $S$ is calculated by equations (8)-(11).

$$
A_{s}=\sqrt{6} \cos \vartheta
$$




$$
\begin{gathered}
\vartheta=\frac{1}{3} \arccos (\sqrt{6} W) \\
W=2^{1.5 \frac{\widetilde{S_{l \jmath}} \widetilde{S_{\jmath k}} \widetilde{S_{k l}}}{S^{3}}} \\
S=\sqrt{2 \widetilde{S_{l \jmath} \widetilde{S_{l \jmath}}}}
\end{gathered}
$$

S Represents the strain rate. After the closure of the RANS equations, the flow through the domain can be determined. For the purposes of simulating the temperature profile through the domain the law of conservation of energy (12) must be included in the model.

$$
\frac{\partial(\rho E)}{\partial t}+\nabla(\rho E v)=f_{b} \cdot v+\nabla \cdot(v \cdot \sigma)-\nabla \cdot q+Z_{E}
$$

With E the total energy per unit mass, $f_{b}$ the resultant body forces per unit volume, $\sigma$ the stress tensor, $q$ the heat flux and $Z_{E}$ the energy source per unit volume.

\section{Solution Algorithm}

The models described are solved in STAR-CCM+ ${ }^{T M}$ by first deriving more useful forms of the formulas using the finite volume method. The stove geometry is divided into a finite amount of control volumes as illustrated by Fig. $\mathbf{6}$. The continuity, momentum, energy, turbulent and all other relevant equations are integrated over the control volume. To calculate the value of variables at the interfaces between two control volumes a central differencing scheme is used. Following mathematical simplifications, matrix algebra is used to calculate all the required variables. The segregated solver in $\mathrm{STAR}-\mathrm{CCM}+{ }^{\mathrm{TM}}$ was chosen for this purpose. The segregated solver is less computationally expensive than a coupled solver for large problems[31][32] since each component of velocity and the value of the pressure is calculated using separate equations. Selecting the segregated solver activates the semi-implicit method for pressure linked equations (SIMPLE) algorithm. A pressure difference is guessed and used to calculate the velocity field vectors of the discretised RANS equations [33]. These values are plugged into a pressure equation, the Poisson equation in the case of STAR-CCM+, to calculate a pressure correction. The correction value from the Poisson equation is added to the initial pressure field guess and the new pressure field is used to calculate a corrected velocity field. All other parameters are calculated using these corrected velocity and pressure values. The corrected pressure is used as the new pressure guess value and the entire process is repeated until both the continuity and momentum equations are converged [34].

\section{Constant determination and specification}

The gas was specified to be $\mathrm{CO}_{2}$ in the physics continuum tree. The inlet boundary type was changed to a velocity inlet after which it was given a magnitude corresponding to the experimental inlet velocity measurement of the specific run to be investigated. A similar approach was followed for the outlet boundary within the gas region, but with the type set to pressure outlet and a constant pressure difference of $0 \mathrm{~Pa}$ with respect to the atmosphere. A total heat source in the bottom coal block was specified and manipulated until the converged model delivered a temperature at the bottom thermocouple in the hopper chamber that is sufficiently close to the experimental measurement at that point. The sphericity of coal was assumed to be 0.79 [35] and was used to calculate the bed void fraction using (13). From the void fraction, the tortuosity of the coal could be approximated using (14) [36].

$$
\begin{gathered}
\phi=1.0-0.864 \phi_{s}+0.2745 \phi_{s}{ }^{2} \\
\xi=\frac{1}{\phi}
\end{gathered}
$$

Here $\phi$ represents the bed void fraction, $\phi_{s}$ the coal sphericity and $\xi$ the tortuosity of the coal bed. Furthermore, the porous inertial and viscous resistance was determined by solving $P_{i}$ and $P_{v}$ in (15) to achieve a pressure drop of $1000 \mathrm{~Pa}$

\begin{tabular}{|c|c|c|}
\hline Constant & Unit & Value \\
\hline Bed porosity & - & 0.48 \\
\hline Heat source $\left(\mathrm{LP}^{\mathrm{a}}, \mathrm{D}^{\mathrm{b}}\right)$ & $W$ & 215 \\
\hline Heat source (LP, C) & $W$ & 290 \\
\hline Heat source $\left(\mathrm{HP}^{\mathrm{c}}, \mathrm{D}\right)$ & $W$ & 390 \\
\hline Heat source $(\mathrm{HP}, \mathrm{C})$ & $W$ & 440 \\
\hline Porous inertial resistance & $\mathrm{kg} / \mathrm{m}^{4}$ & 1900 \\
\hline Porous viscous resistance & $\mathrm{kg} / \mathrm{m}^{3} \cdot \mathrm{s}$ & 4400 \\
\hline $\begin{array}{l}\text { Coal bottom; thermal } \\
\text { conductivity }\end{array}$ & $W / m \cdot K$ & 0.55 \\
\hline $\begin{array}{l}\text { Coal top; thermal } \\
\text { conductivity }\end{array}$ & $W / m \cdot K$ & 2.00 \\
\hline Tortuosity & - & 2.04 \\
\hline $\begin{array}{l}\text { Outlet Pressure relative to } \\
\text { atmospheric pressure }\end{array}$ & $P a$ & 0 \\
\hline Mesh base size & $\mathrm{mm}$ & 10 \\
\hline
\end{tabular}
using the Microsoft Excel $^{\mathrm{TM}}$ solver function. Finally, the thermal conductivity of coal was retrieved from literature of samples between the temperatures of $600^{\circ} \mathrm{C}$ and $1000^{\circ} \mathrm{C}$ [37].

$$
\Delta p=-\rho\left(P_{i}\left|v_{s, n}\right|+P_{v}\right) v_{s, n}
$$

\section{EXPERIMENTAL METHOD}

The coal to be used during the experiments was sieved to ensure all particles were between $19.5 \mathrm{~mm}$ and $26.5 \mathrm{~mm}$, while the coal grade varied between A, B, C and D. Locally bought wood was cut into $10.0 \mathrm{~cm} \times 0.5 \mathrm{~cm}$ chips. As required by the experiment, the required number of woodchips were soaked in paraffin for 24 hours and stored in a plastic container. The exterior of the stove is illustrated in Fig. 7. First, the cooking surface of the stove and the hopper chamber was opened in order to continue with ignition and $1.5 \mathrm{~kg}$ of coal was distributed in the stove to cover the entire grate surface area. 


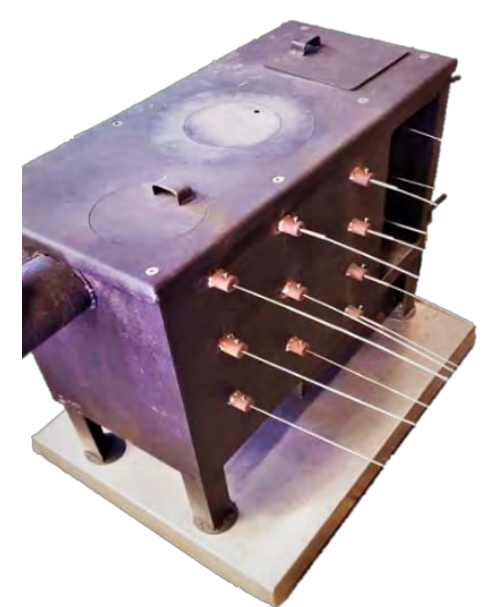

Fig. 7: Stove exterior including the attached thermocouples and the load cell used for mass measurements.

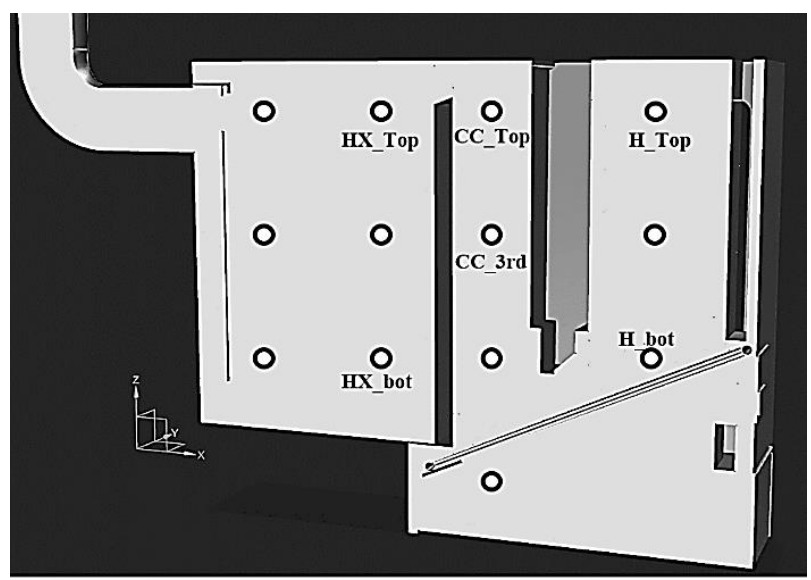

Fig. 8: Thermocouple positions and their corresponding names.

$200 \mathrm{~g}$ Of the woodchips were placed on top of the coal in a horizontal position and was distributed beneath the bridge and on top of the coal bed. An additional $150 \mathrm{~g}$ of small coal pieces were placed on top of the wood after which 1 paraffin-soaked wood chip was placed in the combustion chamber and another beneath the bridge. An additional $100 \mathrm{~g}$ of dry wood chips were placed on top of the coal and wood layers, and a match was lighted and placed inside the combustion chamber using tongs. The cooking surface was then closed, the hopper chamber was left open and the coal could ignite for 15 minutes. After the waiting period, the air controller was fully opened and the hopper was filled to the brim and closed.
TABLE III: AIR OPENING CORRESPONDING TO DIFFERENT RUN TYPES.

\begin{tabular}{cccc}
\hline \hline $\begin{array}{c}\text { Air-opening } \\
(\mathbf{c m})\end{array}$ & $\begin{array}{c}\text { Opening } \\
(\%)\end{array}$ & Run Type & Run no. \\
\hline 0.5 & 25 & Low power & $2,4,5,7,8,9,11,12$ \\
4.0 & 50 & High power & $1,3,6,10$ \\
\hline \hline
\end{tabular}

After a final 30-minute waiting period the air-controller was adjusted to the relevant position for the type of run. 12 Experimental runs were completed during which the coal could combust to completion. The air-controller openings corresponding to the type of run are summarised in TABLE III. After the 30-minute period, grate shakes were done once every 30 minutes for high-power runs and once every hour for low-power runs. The mass loss from the stove was measured using a Combix 1 unit and the data was recorded in 10 second intervals with a CR1000 X datalogger connected to a laptop. The same logger was used to store temperature data measured via K-type thermocouples connected to the stove at the locations illustrated by Fig. 8. The chimney velocity was measured with an S-type pitot tube connected to a Fluke 922 air-flowmeter at an opening located approximately $0.6 \mathrm{~m}$ above the chimney bend. An average velocity was obtained by measuring the chimney velocity across the entire diameter of the pipe. The opening was sealed between measurements with fire proof tape. The inlet velocity to the stove was measured with a Kestrel vane anemometer with the help of a cylinder with a constant diameter of $0.04 \mathrm{~m}$. The cylinder was placed against the inlet while the anemometer was held at the opposing side.

\section{RESUlTS AND DisCUSSION}

\section{A. Flow rate correction}

The volumetric flow rate at the inlet and outlet was calculated by multiplying the velocity with the area of the constant diameter cylinder and the chimney area respectively. This was done to the experimental outputs as well as the model outputs. Furthermore, a correction was added to the model's chimney prediction to account for the increase in volume due to combustion - which was calculated by multiplying the mass loss in $\mathrm{kg} / \mathrm{s}$ between two consecutive measurements by the approximate density of $\mathrm{CO}_{2}$ at the chimney temperature. Model validation and profile analysis were done with the data from the $5^{\text {th }}, 6^{\text {th }}, 8^{\text {th }}$ and $10^{\text {th }}$ experimental runs and the applicable correction factors are provided in TABLE II.

TABLE II: CALCULATION OF THE CORRECTION FACTORS USED TO DETERMINE THE EXIT FLOW RATE.

\begin{tabular}{|c|c|c|c|c|}
\hline Run no. & $\begin{array}{c}\text { Chimney temperature } \\
\left({ }^{\circ} \mathrm{C}\right)\end{array}$ & $\begin{array}{c}\text { Density of } \mathrm{CO}_{2} \\
\left(\mathrm{~kg} / \mathrm{m}^{3}\right)\end{array}$ & $\begin{array}{c}\text { Mass loss } \times 10^{-4} \\
(\mathrm{~kg} / \mathrm{s})\end{array}$ & $\begin{array}{c}\text { Correction value } \times 10^{-4} \\
\left(\mathrm{~m}^{3} / \mathrm{s}\right)\end{array}$ \\
\hline 5 & 127 & 1.326 & 1.42 & 1.07 \\
\hline 6 & 191 & 1.140 & 2.68 & 2.35 \\
\hline 8 & 122 & 1.342 & 1.34 & 1.00 \\
\hline 10 & 178 & 1.173 & 2.30 & 1.96 \\
\hline
\end{tabular}




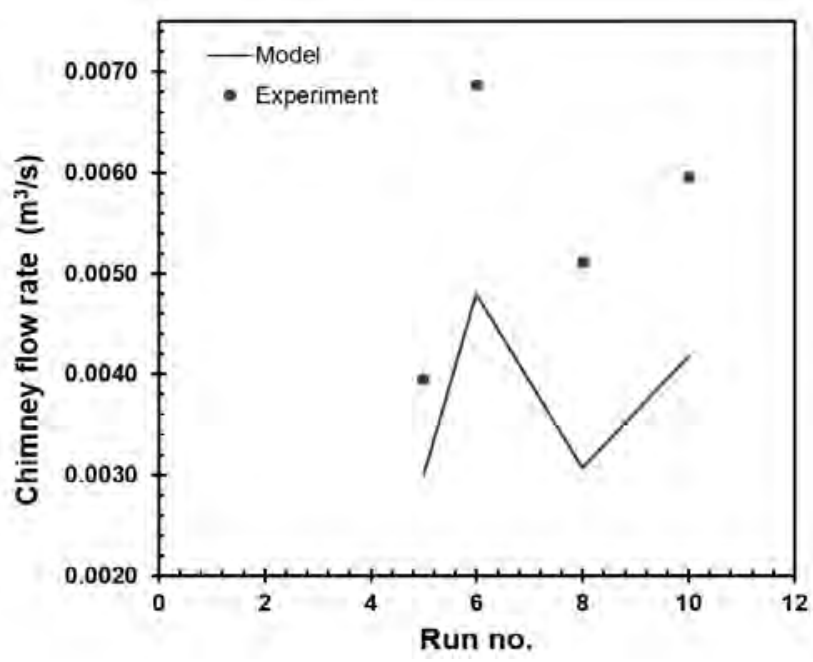

Fig. 9: Comparison between modelled and experimental chimney flow rates.

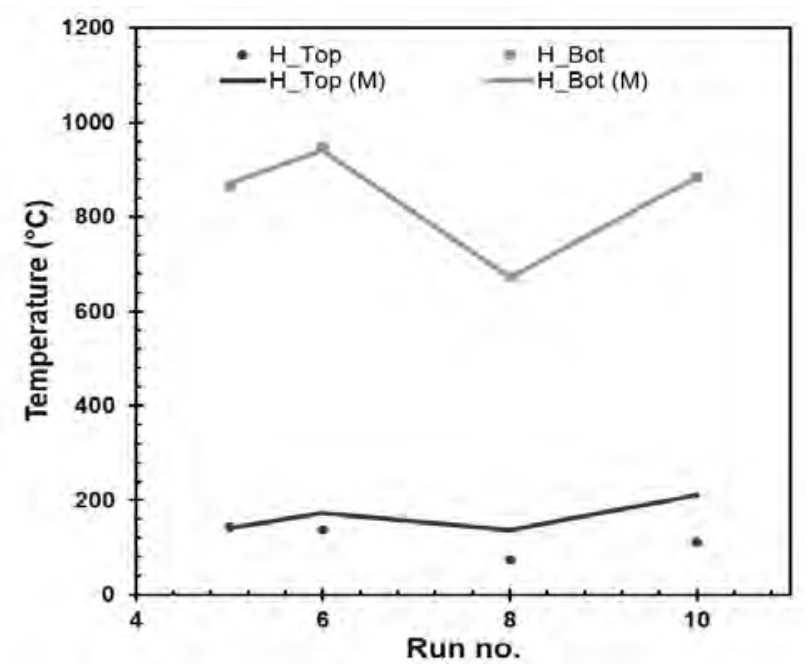

Fig. 10: Comparison between modelled (M) and experimental hopper chamber temperatures.

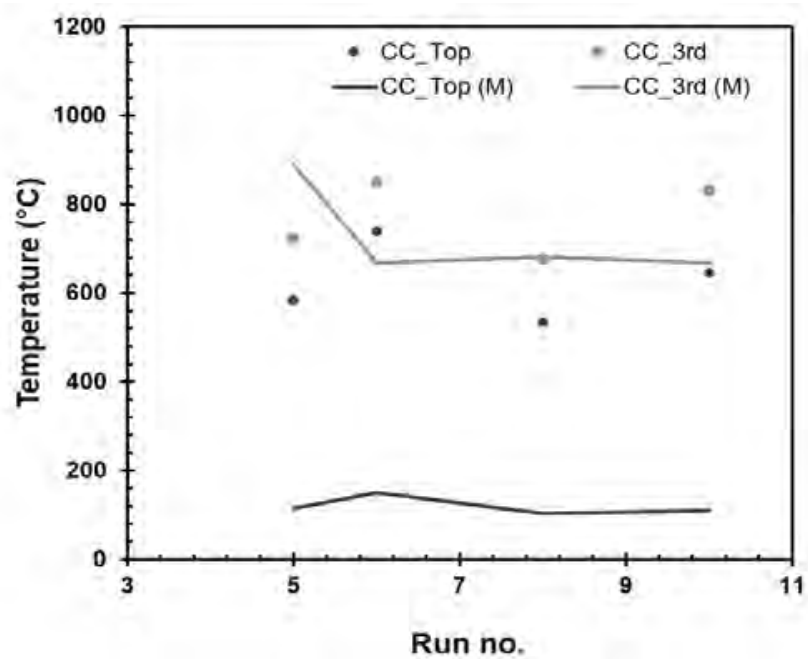

Fig. 11: Comparison between modelled (M) and experimental combustion chamber temperatures.

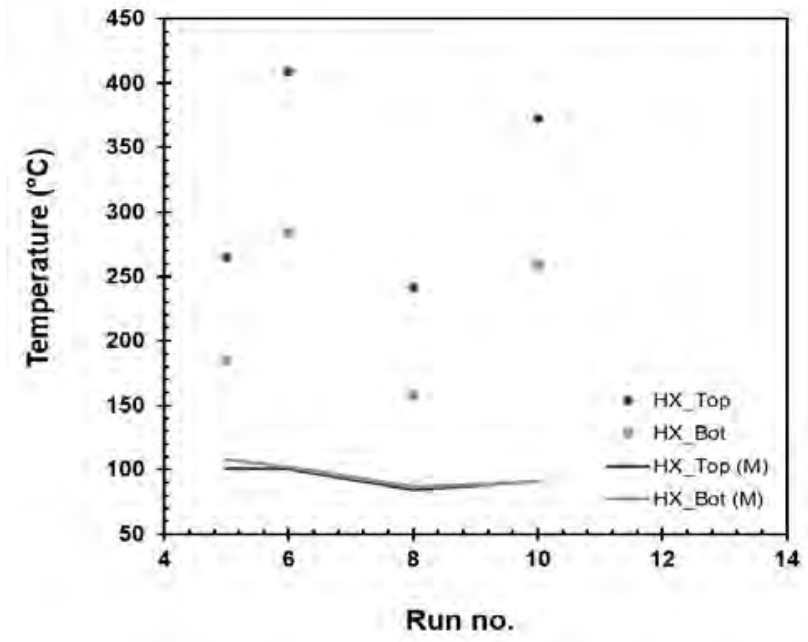

Fig. 12: Comparison between modelled (M) and experimental heat exchanger chamber temperatures.

\section{B. Model validation}

The comparison between predicted and experimental chimney flow rates is provided in Fig. 9. Even with a correction factor, the model output underestimates the flow-rate in the chimney by an average of $30 \%$. However, the trend of the simulation prediction agrees with that of the experimental data. The inaccurate prediction results from the absence of a combustion model that would more accurately predict the volume change due to combustion products in the exit gas. A constant density model was also chosen in the model which further influences the model's output. The comparison between predicted and experimental hopper temperatures is provided in Fig. 10. Since the heat source within the stove was manipulated to match the temperature at the bottom thermocouple position in the hopper, the model has a near perfect fit to this point for all runs as illustrated by H_Bot. Although the modelled temperatures in the top of the hopper chamber visually deviate slightly from the observed temperatures, the deviation is due to the porous region selection that heats up the gas in this specified region to emulate the presence of a porous media (like a bed of coal particles). If a porous media model was used to simulate the presence of coal, the predicted values would more closely reflect the experimental values. The comparison between predicted and experimental combustion chamber temperatures is provided in Fig. 11. The temperature prediction of the $3^{\text {rd }}$ thermocouple is within a suitable temperature range while the top thermocouple prediction deviates by as much as $311{ }^{\circ} \mathrm{C}$ from measured data. This is due to the absence of a combustion model that would account for the additional combustion heat transfer into the flue gas. The comparison between predicted and experimental combustion chamber temperatures is provided in Fig. 12. The temperature prediction is not representative of the experimental data and the inaccuracy of the model can be ascribed to the low temperature prediction at the top of the combustion chamber previously discussed. When considering the data, the inability of the model to accurately predict temperature, prevents any further investigation regarding the inefficient heat distribution throughout the stove. 


\section{Velocity profile analysis}

Since the predicted velocity profile of each run under investigation was similar, the profile for run 10 is provided in Fig. 13. Very low flow is observed in the hopper chamber, which is to be expected since no path is available for the gas to exit at the top, and a low pressure drop of $1000 \mathrm{~Pa}$ was specified when approximating the inertial and viscous resistances of the porous region. At the top of the combustion chamber, the flow is reversed and the gas flow from the top of the chamber collides with that from the bottom causing recirculation just below the chamber opening to the heat exchanger. The gas flowing through the inlet to the heat exchanger chamber, reaches velocities up to $65 \%$ of the maximum velocity, after which most gas enters the chimney through the top chimney opening. By comparing Fig. 13 to a temperature profile generated by the model as shown in Fig. 14, it becomes apparent that the low flow through the hopper chamber, and thus the absence of convective heat transfer from the coal to the gas, could be causing the increased temperature in this chamber.

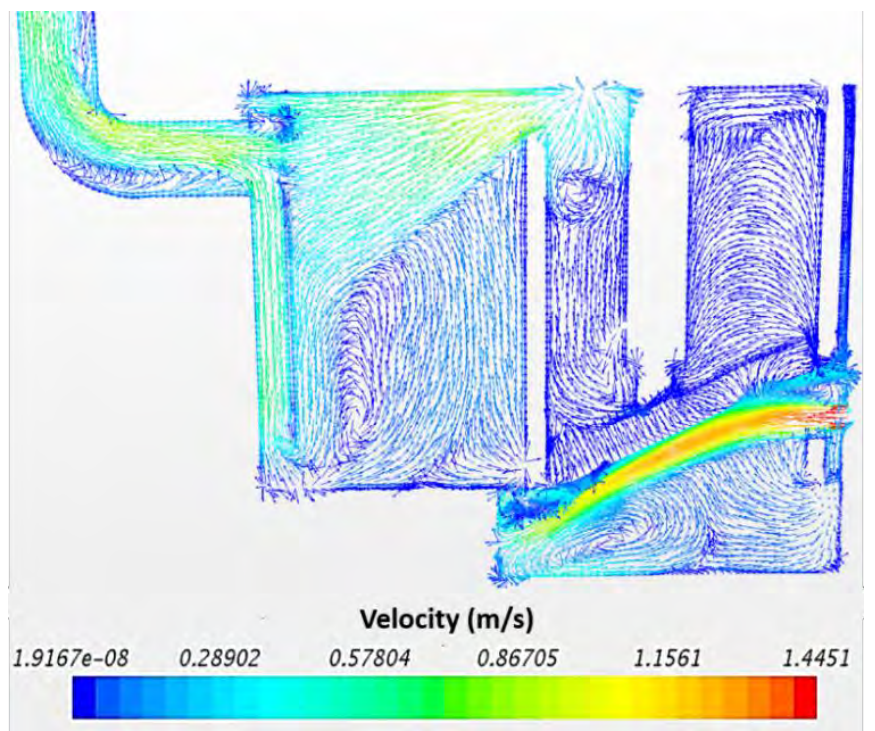

Fig. 13: Predicted velocity profile inside the coal stove.

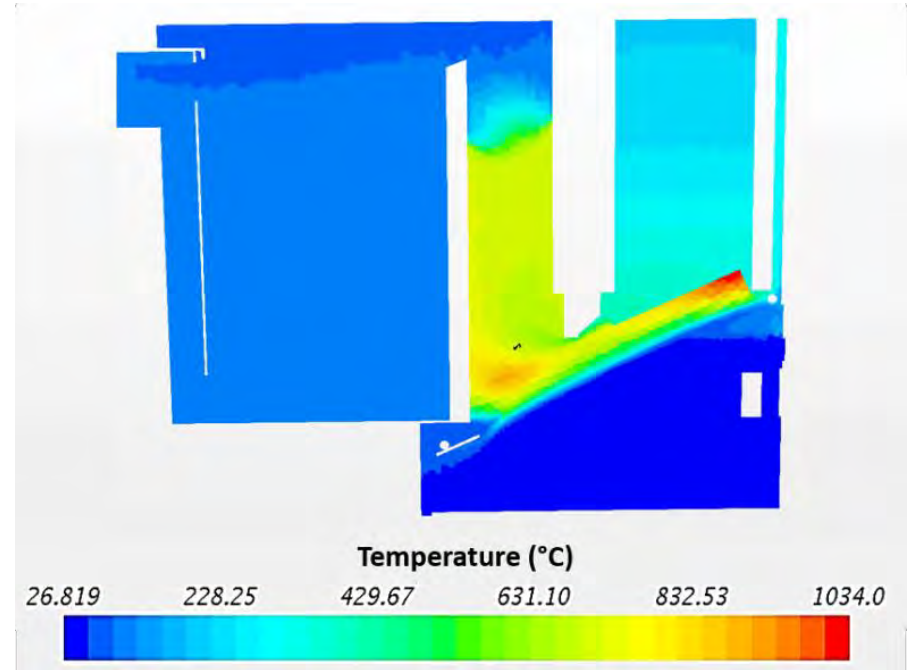

Fig. 14: Predicted temperature profile inside the coal stove.

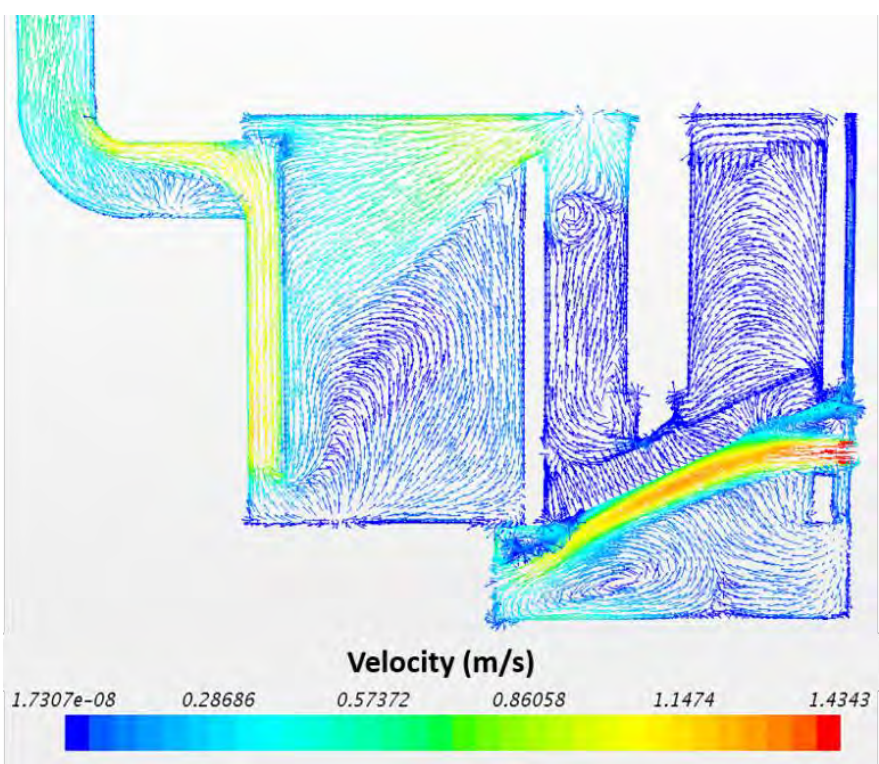

Fig. 15: Predicted velocity profile inside the stove with the first modification. 


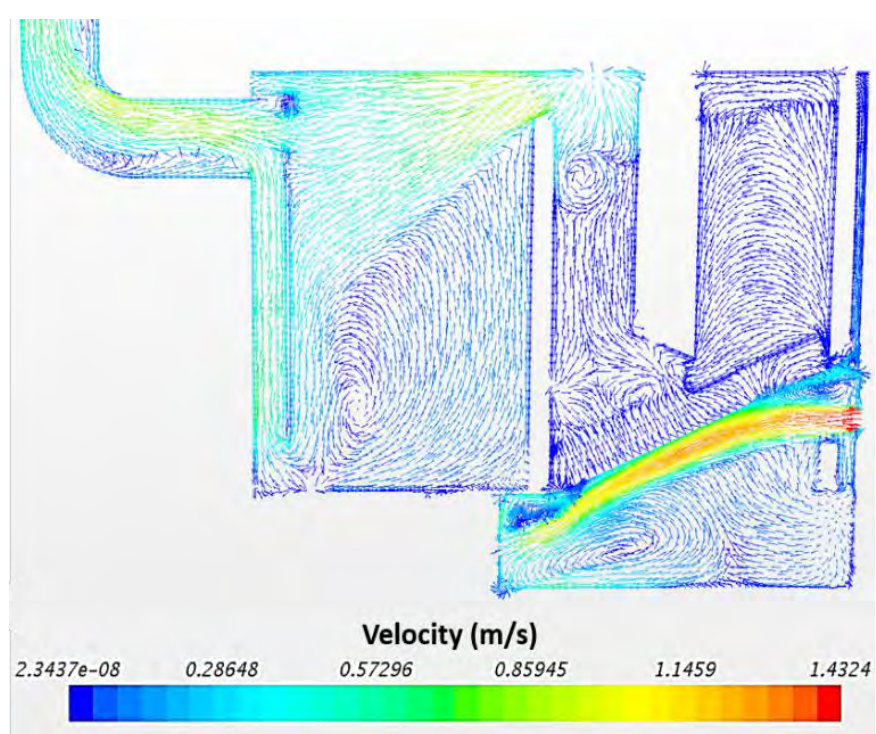

Fig. 16: Predicted velocity profile inside the stove with the second modification.

However, due to the temperature predicting limitations of the model, making a conclusion regarding the cause behind the inefficient distribution could be biased. All the regions where a low velocity is observed seem to reach high temperatures according to the current simulation.

\section{Stove modifications}

The velocity profile of the first modified stove is given in Fig. 15. The velocity inside the chimney entrance reaches a value of approximately $1.1 \mathrm{~m} / \mathrm{s}$ due to the absence of a top entrance in the exhaust channel inside the stove feeding the chimney. The recirculation in the combustion chamber is still present and the velocity throughout the coal bed is the same as that of the unmodified stove. The velocity profile of the second modified stove is provided in Fig. 16.

The velocity profile is the same as the profile of the unmodified stove except for the bridge region, which is the section inside the stove that controls the flow of coal particles from the hopper region into the combustion chamber. In the case of the unmodified stove, the entering air is directed towards the hopper chamber once colliding with the bridge, after which the pressure in the hopper chamber forces the gas through the small opening below the bridge towards the combustion chamber. For the modified stove most of the entering air flows in the direction of the combustion chamber with only a fraction reversing towards the hopper chamber. These phenomena are illustrated by Fig. 17 and Fig. 18 respectively. Despite the change in velocity profiles, neither of the stove alterations had a noteworthy effect on the predicted temperature profile in the stove. The comparison between the temperatures at each of the investigated thermocouples for the unmodified and two modified stoves are illustrated by Fig. 19 .

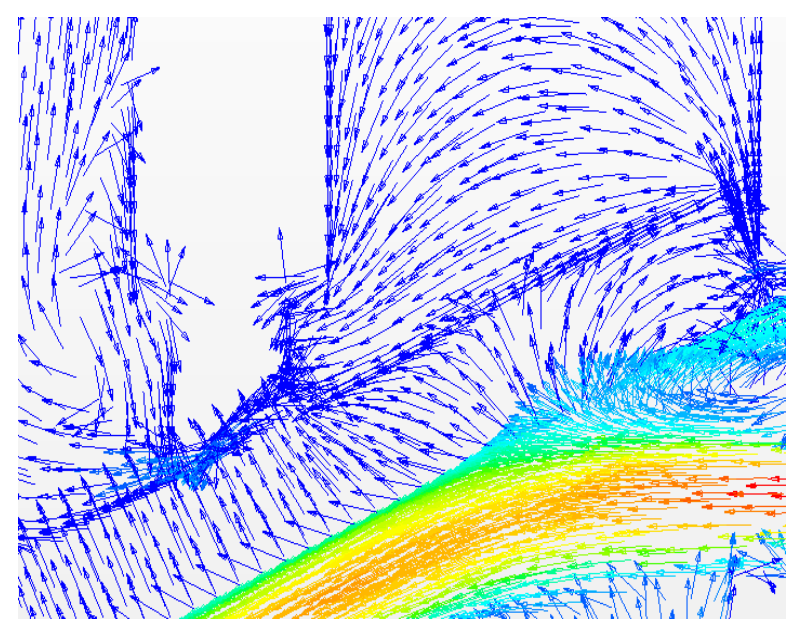

Fig. 17: Enlarged view of the velocity profile around the bridge of the unmodified stove.

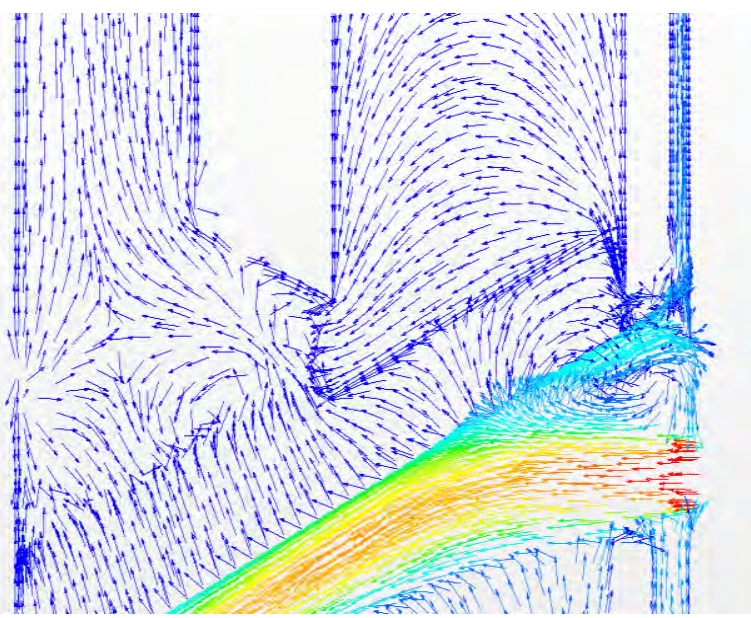

Fig. 18: Enlarged view of the velocity profile around the bridge with the second modification.

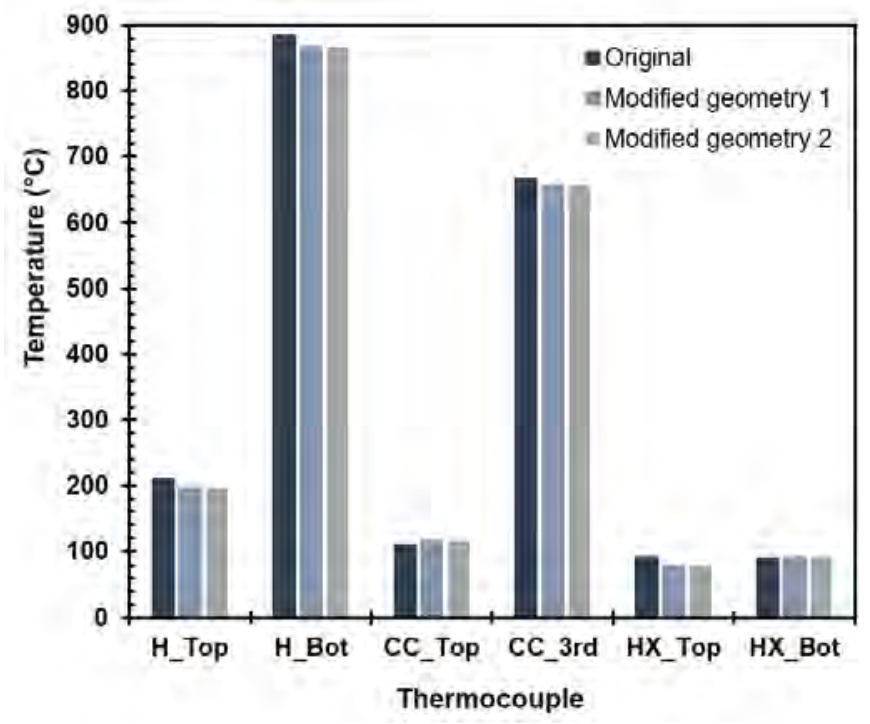

Fig. 19: Predicted temperatures at every thermocouple of the unmodified and two modified stove geometries. 


\section{CONCLUSION}

At a grid size of $10 \mathrm{~mm}$ and a convergence time of 1 hour, the model proved to be representative of the behaviour of the velocity through the stove. The temperature distribution was predicted with limited accuracy, especially in the heat exchanger chamber. Based on the current model, the increased temperature in the hopper chamber is related to the low velocity of the gas through the region and the resulting absence of convective heat transfer. The primary aim of this reconnaissance study of determining the reason for the poor energy distribution using the model, was partially fulfilled, when considering the predicting capability of the simulation. The model prediction capability can be improved by including a combustion model and introducing a comprehensive heat transfer model, through the stove walls and in the packed bed of combusting particles. Results validation by comparison with external temperature measurement as well as the temperature and composition of the gas in the chimney will also benefit the modelling effort. The ease by which modified geometries can be investigated with this method has been demonstrated and it is recommended that the findings of this work be used as a stepping stone towards a simulation that more accurately represents the experimental data. Once such a simulation has been created, the stove modifications can be repeated and adapted to aid in the improvement of the semi-continuous coal stove.

\section{REFERENCES}

[1] D.C. Baruah and C.C. Enweremadu, "Prospects of decentralized renewable energy to improve energy access: A resource-inventory-based analysis of South Africa," Renewable and Sustainable Energy Reviews, vol. 103, no. C, pp. 328-341, April 2019. https://doi.org/10.1016/j.rser.2019.01.006

[2] T.N. Mdluli and C.H. Vogel, "Challenges to achieving a successful transition to a low carbon economy in South Africa: examples from poor urban communities," Mitigation and Adaptation Strategies for Global Change, vol. 15, no. 3, pp. 205-222, March 2010.

https://doi.org/10.1007/s11027-009-9195-4

[3] H. Meintjies, "Washing machines make lazy women," Journal of Material Culture, vol. 6, no. 3, pp. 345-363, Nov. 2001. https://doi.org/10.1177/135918350100600304

[4] C. Muller and H. Yan, "Household fuel use in developing countries: Review of theory and evidence," Energy Economics, vol. 70, no. 1, pp. 429-439, Feb. 2018. https://doi.org/10.1016/j.eneco.2018.01.024

[5] E.E. Adaji, W. Ekezie, M. Clifford and R. Phalkey, "Understanding the effect of indoor air pollution on pneumonia in children under 5 in lowand middle-income countries: a systematic review of evidence," Environmental Science and Pollution Research, vol. 26, no. 4, pp. 3208-3225, Feb. 2019. https://doi.org/10.1007/s11356-018-3769-1

[6] T. Kühn, J.R. Bunt, H.W.J.P. Neomagus, S.J. Piketh, R.C. Everson and S. Coetzee, "Coal-derived low smoke fuel assessment through coal stove combustion testing," Journal of Analytical and Applied Pyrolysis, vol. 126, no. 1, pp. 158-168, July 2017 https://doi.org/10.1016/j.jaap.2017.06.012

[7] C.A. Roden, T.C. Bond, S. Conway, A.B.O. Pinel, N. MacCarty and D. Still, "Laboratory and field investigations of particulate and carbon monoxide emissions from traditional and improved cookstoves," Atmospheric Environment, vol. 43, no. 6, pp. 1170-1181, Feb. 2009. https://doi.org/10.1016/j.atmosenv.2008.05.041

[8] N. Dendup and T.H. Arimura, "Information leverage: The adoption of clean cooking fuel in Bhutan," Energy Policy, vol. 125, no. 1, pp. 181-195, Feb. 2019. https://doi.org/10.1016/j.enpol.2018.10.054

[9] Z. Youcai, Pollution Control and Resource Recovery: Municipal Solid Wastes Incineration: Bottom Ash and Fly Ash, 1st ed. Oxford, UK: Elsevier, 2017, ch 2, pp. 61-82.

https://doi.org/10.1016/B978-0-12-812165-8.00002-0

[10] N.D. Duranay, and D. Pehlivan, "Combustion of lignite carbon under agitation," Fuel Processing Technology, vol. 86, no. 8, pp. 913-923, May 2005.

https://doi.org/10.1016/j.fuproc.2004.10.002

[11] S.C. Bhattacharya, D.O. Albina and P.A. Salam, "Emission factors of wood and charcoal-fired cookstoves," Biomass and Bioenergy, vol. 23, no. 6, pp. 453-469, Dec. 2002. https://doi.org/10.1016/S0961-9534(02)00072-7

[12] K. Lask, K. Booker and A. Gadgil, "Lessons learned from a comparison study of charcoal stoves for Haiti," Sustainable Energy Technologies and Assessments, vol. 22, no. 1, pp. 188-193. Aug. 2017. https://doi.org/10.1016/j.seta.2017.02.008

[13] U. Kleinhans, C. Wieland, F.J. Frandsen and H. Spliethoff, "Ash formation and deposition in coal and biomass fired combustion systems: Progress and challenges in the field of ash particle sticking and rebound behaviour," Progress in Energy and Combustion Science, vol. 68, no. 1, pp. 65-168, Sep. 2018. https://doi.org/10.1016/j.pecs.2018.02.001

[14] L. Tian, Q. Lan, D. Yang, X. He, I.T.S. Yu, and S.K. Hammond, "Effect of chimneys on indoor air concentrations of PM10 and benzo[a]pyrene in Xuan Wei, China," Atmospheric Environment, vol. 43, no. 21, pp. 3352-3355, July 2009. https://doi.org/10.1016/j.atmosenv.2009.04.004

[15] C. Liu, C. Zhang, Y. Mu, J. Liu and Y. Zhang, "Emission of volatile organic compounds from domestic coal stove with the actual alternation of flaming and smoldering combustion processes," Environmental Pollution, vol. 221, no. 1, pp. 385-391, Feb. 2017. https://doi.org/10.1016/j.envpol.2016.11.089

[16] F.K. Mokgotho, "Evaluation of the performance of the new semi continuous coal stove: Coal burn-off," Final year project, Dept. Chem. Eng., NWU., Potchefstroom, South-Africa, 2018.

[17] C. Strydom, "Evaluation of the combustion behavior in a semi-continuous stove," Final year project, Dept. Chem. Eng., NWU., Potchefstroom, South-Africa, 2018.

[18] S.V. Patankar, Numerical Heat Transfer and Fluid Flow, 1st ed. Washington D.C., USA: Hemisphere Publishing Corporation, 1980, ch 1, pp. 1-9.

[19] C.K.W. Ndiema, F.M. Mpendazoe, F.M. and A. Williams, "Emission of pollutants from a biomass stove," Energy Conversion and Management, vol. 39, no. 13, pp. 1357-1367, Sep. 1998. https://doi.org/10.1016/S0196-8904(98)00008-9

[20] R, Buczyński, R. Weber, and A. Szlęk, "Innovative design solutions for small-scale domestic boilers: Combustion improvements using a CFD-based mathematical model," Journal of the Energy Institute, vol. 88, no. 1, pp. 53-63, Feb. 2015. https://doi.org/10.1016/j.joei.2014.04.006

[21] M. Saha, B.B. Dally, P.R. Medwell, and A. Chinnici, "Burning characteristics of Victorian brown coal under MILD combustion conditions," Combustion and Flame, vol. 172, no. 1, pp. 252-270, Aug. 2016. https://doi.org/10.1016/j.combustflame.2016.07.026

[22] M.M. Sardouei, H. Mortezapour, and K. Jafari Naeimi, "Temperature distribution and efficiency assessment of different PVT water collector designs" Sadhana, vol. 43, no. 6, pp. 73-84, June 2018. https://doi.org/10.1007/s12046-018-0826-x

[23] S. Echi, A. Bouabidi, Z. Driss, and M Salah Abid, "CFD simulation and optimization of an industrial boiler," Energy, vol. 169, no. 1, pp. 105-114, Feb. 2019. https://doi.org/10.1016/j.energy.2018.12.006

[24] M. Kumar, R.K. Sahoo and S.K. Behera, "Design and numerical investigation to visualize the fluid flow and thermal characteristics of non-axisymmetric convergent nozzle," Engineering Science and Technology, an International Journal, vol. 22, no. 1, pp. 294-312, Feb. 2019. https://doi.org/10.1016/j.jestch.2018.10.006

[25] C.D. Argyropoulos and N.C. Markatos, "Recent advances on the numerical modelling of turbulent flows," Applied Mathematical Modelling, vol. 39, no. 2, pp. 693-732, Jan. 2015. https://doi.org/10.1016/j.apm.2014.07.001 
[26] J.R. Welty, G.L. Rorrer, and D.G. Foster, Fundamentals of Momentum, Heat and Mass Transfer, 6th ed. Singapore, Asia: John Wiley \& Sons, 2015, ch 12, pp. 147-178.

[27] H. Xiao and P. Cinnella, "Quantification of model uncertainty in RANS simulations: A review," Progress in Aerospace Science, vol. 108, no. 1, pp. 1-31, July 2019.

https://doi.org/10.1016/j.paerosci.2018.10.001

[28] M. Casey and T. Wintergerste. (2000) "ERCOFTAC Special interest group on quality and trust in industrial CFD," [Online] Available: https://www.scribd.com/document/286278140/ercoftac-best-practice-gui de-pdf

[29] P.K. Kundu, I.M. Cohen and D.R. Dowling, Fluid Mechanics, 6th ed. London, UK: Elsevier, 2015, ch 12, pp. 603-697. https://doi.org/10.1016/B978-0-12-405935-1.00012-5

[30] M. Lateb, C. Masson, T. Stathopoulos, and C. Bédard, "Comparison of various types of $\mathrm{k}-\mathrm{e}$ models for pollutant emissions around a two-building configuration" Journal of Wind Engineering and Industrial Aerodynamics, vol. 115, no. 1, pp. 9-21, Apr. 2013. https://doi.org/10.1016/j.jweia.2013.01.001

[31] A. Pascau, C. Pérez, and F.J. Serón, "A comparison of segregated and coupled methods for the solution of the incompressible Navier-Stokes equations," Numerical Methods in Biochemical Engineering, vol. 12, no. 10, pp. 617-630, Oct. 1996.

https://doi.org/10.1002/(SICI)1099-0887(199610)12:10<617::AID-CN $\mathrm{M} 10>3.3 . \mathrm{CO} ; 2-\mathrm{A}$

[32] H.T. Honório, and C.R. Maliska, "On the performance of coupled and segregated methods for solving two-dimensional incompressible flows employing unstructured grids," presented at the Brazilian congress of thermal sciences and engineering conference, Brazil, Nov. 10-13, 2014.

[33] S.V. Patankar and D.B. Spalding, "A calculation procedure for heat mass and momentum transfer in three dimensional parabolic flows," International Journal of Heat and Mass Transfer, vol. 15, no. 10, pp. 1787-1806, Oct. 1972. https://doi.org/10.1016/0017-9310(72)90054-3

[34] H.K. Versteeg and W. Malalasekera, An introduction to computational fluid dynamics: The finite volume method, 2nd ed. Essex: Pearson Education Limited, 2007, ch 6, pp. 178-211.

[35] A. Luckos and A. Koekemoer, "On the sphericity of coal and char particles," presented at the International Fluidization South Africa conference, South-Africa, Nov. 16-17, 2015.

[36] H. Fatehi and X.S. Bai, "Gasification and combustion of biomass: Physical description and mathematical modelling," in Handbook of clean energy systems, J. Yan, Ed. West Sussex: John Wiley \& Sons Ltd, 2014, pp. 1254-1277.

[37] F. Patisson, E. Lebas, F. Hanrot and D. Ablitzer, "Coal pyrolysis in a rotary kiln: Part 1. Model of the pyrolysis of a single grain," Metallurgical and Materials Transactions B, vol. 32, no. 2, pp. 381-390, Apr. 2000. https://doi.org/10.1007/s11663-000-0056-5 